\title{
rommhalina
}

(8)

Cefaleias

Autor(es): $\quad$ Vasconcelos, Mónica

Publicado por: Imprensa da Universidade de Coimbra

URL

persistente: URI:http://hdl.handle.net/10316.2/43136

DOI: $\quad$ DOI:https://doi.org/10.14195/978-989-26-1300-0_35

Accessed : $\quad$ 26-Apr-2023 01:52:12

A navegação consulta e descarregamento dos títulos inseridos nas Bibliotecas Digitais UC Digitalis, UC Pombalina e UC Impactum, pressupõem a aceitação plena e sem reservas dos Termos e Condições de Uso destas Bibliotecas Digitais, disponíveis em https://digitalis.uc.pt/pt-pt/termos.

Conforme exposto nos referidos Termos e Condições de Uso, o descarregamento de títulos de acesso restrito requer uma licença válida de autorização devendo o utilizador aceder ao(s) documento(s) a partir de um endereço de IP da instituição detentora da supramencionada licença.

Ao utilizador é apenas permitido o descarregamento para uso pessoal, pelo que o emprego do(s) título(s) descarregado(s) para outro fim, designadamente comercial, carece de autorização do respetivo autor ou editor da obra.

Na medida em que todas as obras da UC Digitalis se encontram protegidas pelo Código do Direito de Autor e Direitos Conexos e demais legislação aplicável, toda a cópia, parcial ou total, deste documento, nos casos em que é legalmente admitida, deverá conter ou fazer-se acompanhar por este aviso.

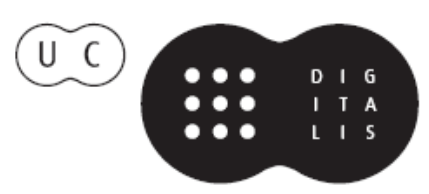




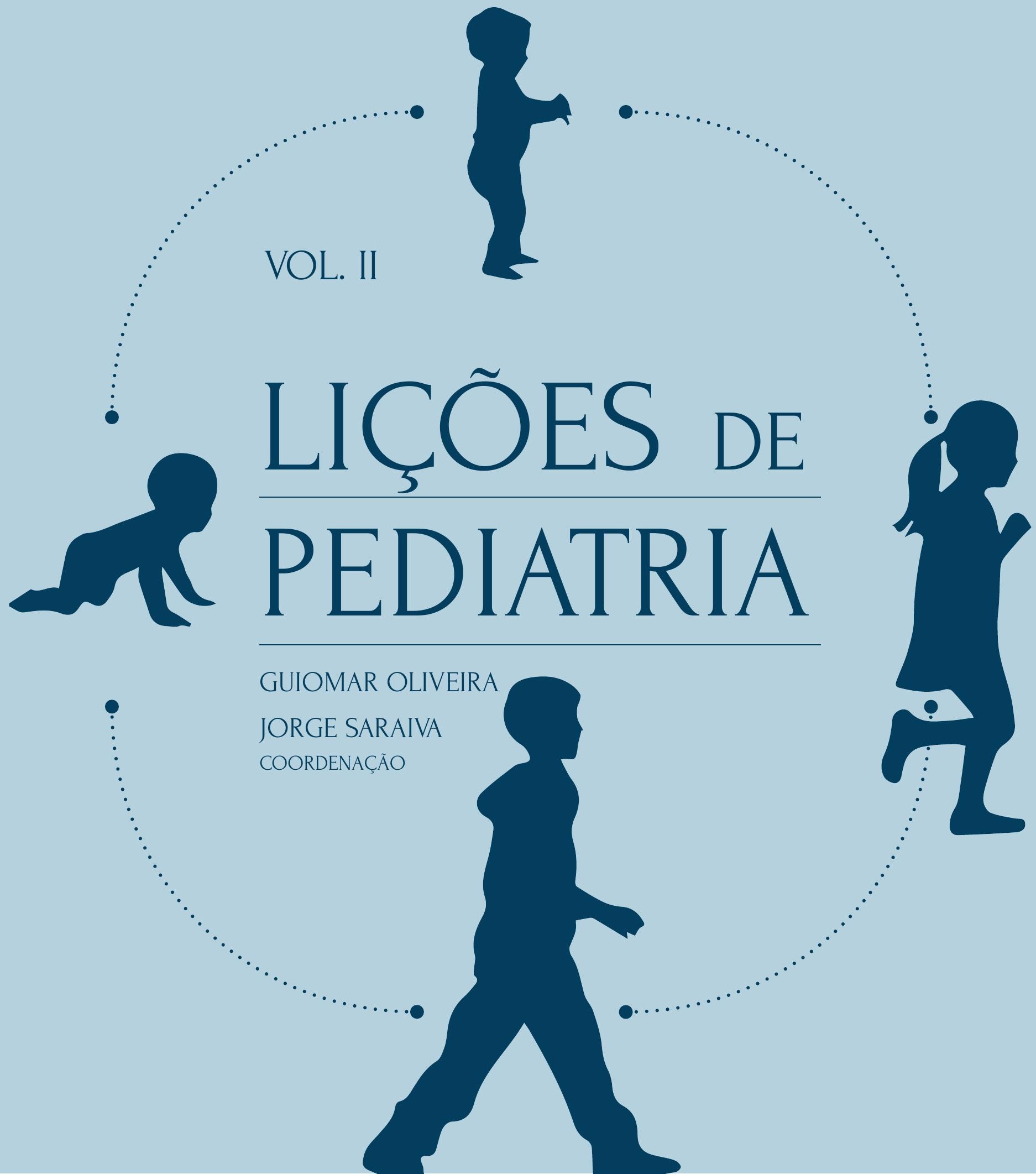


Capítulo 35.

Cefaleias
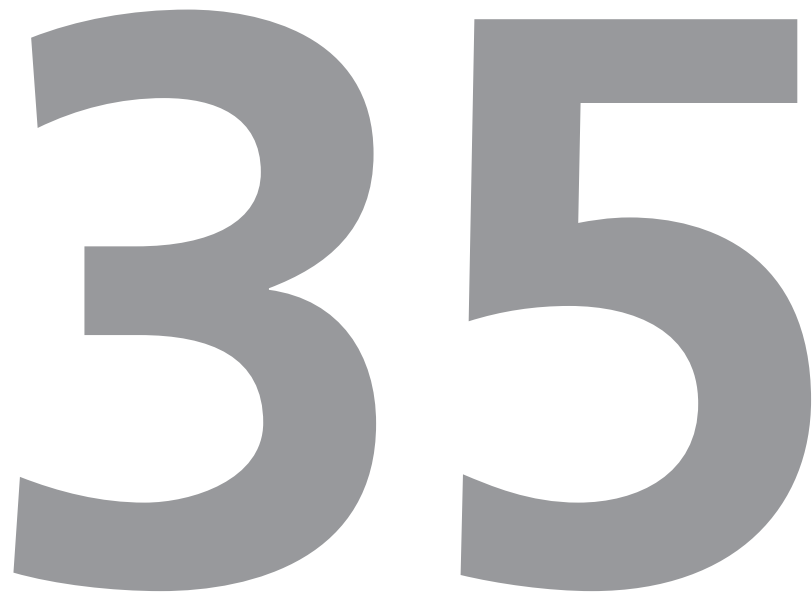

\section{Mónica Vasconcelos}




\subsection{CONTEXTO}

A cefaleia é uma das queixas mais frequentes na população em geral e, em particular, na idade pediátrica. É um sintoma pouco comum antes dos quatro anos e a sua incidência relaciona-se de uma forma positiva com o aumento da idade, estimando-se que atinja 15 a $45 \%$ das crianças no período pré-escolar e escolar, valor este que ascende a 50 a 80 \% na adolescência.

A correta caraterização da cefaleia nos mais novos é muitas vezes difícil tendo em conta os aspetos maturacionais neurobiológicos e psicológicos envolvidos e também porque a criança tem dificuldade em expressar as queixas álgicas e a sua intensidade, em descrever detalhadamente os sintomas e em reconhecer as manifestações associadas. A criança apenas vai conseguir descrever os sintomas de acordo com o seu desenvolvimento intelectual e experiência.

No entanto, é preciso reconhecer a importância das cefaleias e avaliar a sua repercussão no desenvolvimento psicológico, no desempenho escolar, na atenção e na interação social.

\subsection{DESCRIÇÃO DO TEMA}

\subsubsection{O que provoca a dor?}

As principais estruturas dentro do crânio sensíveis à dor são os vasos sanguíneos, através da sua vasodilatação, inflamação, tração e deslocamento. O aumento da pressão intra-craniana leva à dor essencialmente por tração e deslocamento das artérias intra-cranianas. A transmissão da dor a partir dos vasos intracranianos supratentoriais faz-se através do nervo trigémio, enquanto que a transmissão a partir dos vasos infrantentoriais faz-se através dos três primeiros nervos cervicais. O parênquima cerebral, seu epêndima e as meninges (com exceção da dura) não têm recetores para a dor.

As estruturas extra-cranianas que provocam dor são a pele, o tecido subcutâneo, os músculos e as artérias do couro cabeludo. Os ossos do crânio são insensíveis mas o periósteo, especialmente nos seios e junto aos dentes, é doloroso quando inflamado. Os músculos que estão ligados ao crânio provocam dor provavelmente por contração prolongada, nomeadamente os extensores do pescoço, o masseter e os músculos frontais e temporais.

A dor das raízes cervicais e dos nervos cranianos é geralmente devida a um mecanismo de tração por lesão ou malformação.

\subsubsection{Classificação das cefaleias}

A classificação mais frequentemente utilizada é a da International Headache Society (IHS), sendo a revisão mais recente de 2013 (a primeira data de 1988 e a segunda de 2004). Esta classificação apresenta 196 diagnósticos possíveis de cefaleias, dos quais 113 foram descritos na população pediátrica. De acordo com a etiologia classifica as cefaleias em primárias, ou seja, intrínsecas ao sistema nervoso central e secundárias, estas atribuídas diretamente a outra causa (associação causa-efeito com uma etiologia específica). As primárias têm habitualmente início na infância, na adolescência ou no início da vida adulta, sendo as mais frequentes a enxaqueca e as cefaleias de tensão. Quanto às cefaleias secundárias, estas 
podem ser sintoma de uma grande variedade de patologias, sendo nesta idade mais comuns as secundárias a infeções. Um doente pode, no entanto, ter uma cefaleia primária que tenha sido exacerbada por uma causa secundária (i.e. cefaleia pós-traumática num doente com enxaqueca). Numa pequena percentagem de casos (0,4 a 4\%) uma cefaleia aguda ou crónica pode ser o sintoma de apresentação de uma doença intracraniana grave.

Factos a reter:

- Cefaleias Primárias (idiopáticas). Não há lesão orgânica. Tratar cefaleia!

- Cefaleias Secundárias - cefaleia é um sintoma duma patologia subjacente.

Do ponto de vista prático quando uma criança recorre à consulta ou ao serviço de urgência com estas queixas, é fundamental tentar perceber qual é o padrão evolutivo das cefaleias: agudas, recorrentes, crónicas (progressivas ou não progressivas).

\subsubsection{Classificação das cefaleias segundo o padrão evolutivo}

As cefaleias agudas são aquelas que mais frequentemente recorrem ao serviço de urgência, quadro 1. Na grande maioria dos casos são crianças com febre associada a síndromes gripais ou infeções respiratórias superiores. Nestes casos, é sempre essencial excluir uma infeção do sistema nervoso central, nomeadamente uma meningite. As cefaleias de grande intensidade descritas como lancinantes, "a pior cefaleia alguma vez sentida", são sempre um sinal de alerta e obriga a suspeitar de uma possível hemorragia intra-craniana.

\section{"Life-threatening"}

- Infeção sistema nervoso central (meningite, encefalite, abcesso cerebral)

- Hemorragia subaracnoideia (trauma, malformações vasculares, distúrbios hematológicos)

- Traumatismos (acidentais ou não): hemorragia intracraniana

- Hidrocefalia

- Disfunção de shunt ventriculo-peritoneal

\section{Comuns}

- Síndrome febril

- Infeção das vias aéreas superiores, otite, faringite, sinusite

- Infeção dentária

- Primeiro episódio de enxaqueca

- Traumatismo minor

\section{Outras}

- Tóxicos / abuso substâncias (monóxido de carbono,...)

- Pós-ictal

- Hipertensão arterial

Quadro 1. Causas de cefaleias agudas.

Causas de cefaleias recorrentes incluem a enxaqueca, síndromes periódicos associados à enxaqueca, a cefaleia tipo tensão, "cluster headache", disfunção temporo-mandibular e a causada por fármacos e drogas.

\section{As cefaleias com evolução progressi-} va são sempre motivo de preocupação e obrigam a excluir um processo orgânico com hipertensão intra-craniana, nomeadamente lesão 
ocupando espaço (tumor, abcesso, hematoma, ...). Os tumores infra-tentoriais (da fossa posterior) são os que mais frequentemente dão uma clínica de hipertensão intra-craniana por obstrução. Os mais frequentes são o astrocitoma do cerebelo, o meduloblastoma, o ependimoma e o glioma da protuberância. Nestes casos, a cefaleia (por vezes occipital) pode ser o primeiro sintoma, mas a criança apresenta frequentemente náuseas e vómitos matinais, irritabilidade ou alterações do comportamento e/ou do desempenho escolar. Os sinais neurológicos como diplopia, estrabismo, ataxia ou défices focais podem aparecer muito mais tarde. A fundoscopia é funtamental para excluir a existência de estase papilar.

A hipertensão intracraniana benigna idiopática (pseudotumor cerebri) ou secundária (endocrinopatia, medicamentosa, doença sistémica) também cursa com sinais e sintomas de hipertensão intra-craniana, quadro 2. O exame neurológico pode mostrar apenas estase papilar ou, adicionalmente, paralisia do VI par uni ou bilateral. Nestes casos o exame de neuroimagem cerebral é normal e uma punção lombar (PL) com manometria revela uma pressão de liquor muito elevada.

\section{As cefaleias crónicas não progressivas} caracterizam-se por uma duração superior a 15 dias por mês durante três meses, com a duração de pelo menos quatro horas por dia. São mais frequentes no sexo feminino. Estão habitualmente associadas a comorbilidades (abuso medicamentoso, faltas à escola, deterioração do desempenho escolar, fadiga, dor abdominal, artralgias, tonturas, síncopes, obesidade, perturbação do sono,...). Exemplos são a enxaqueca crónica e a cefaleia de tensão crónica. Na adolescência são

\section{Características das cefaleias que sugerem hipertensão intracraniana}

- Cefaleias persistentes

- Cefaleias noturnas ou presentes ao despertar

- Aumento da frequência e/ ou gravidade das queixas

- Existência de vómitos associados

- Agravamento das queixas com a tosse ou mudanças de posição

Quadro 2. Características das cefaleias que sugerem hipertensão intracraniana.

frequentes as cefaleias secundárias a excesso de analgésicos e as relacionadas com a privação de cafeína e a habituação a refrigerantes (colas).

Como já foi dito a classificação das cefaleias segundo a International Classification Headache Disorder (ICHD) divide as cefaleias em primárias e secundárias, quadro 3.

Destas, vamos referir apenas as causas de cefaleias com que habitualmente lidamos na prática clínica diária.

\subsubsection{Enxaqueca}

A enxaqueca constitui o tipo de cefaleia primária mais comum, com uma prevalência de 5 a 20\% na idade escolar e na adolescência e de $2,5 \%$ no período pré-escolar. A fisiopatologia subjacente parece ser de origem neurovascular (vascular e inflamação neurogénica). Existe um componente hereditário muito importante, com 


\section{Cefaleias Primárias}

- Enxaqueca

- Cefaleias de tensão

- Cefalalgias autonómicas do trigémio (cluster, hemicrânia paroxística, SUNCT, SUNA)

- Outras cefaleias primárias

\section{Cefaleias Secundárias}

- Traumatismo encefálico e/ou cervical

- Doença vascular craniana / cervical

- Doença intracraniana não vascular

- Uso de substâncias ou sua privação

- Infeção

- Alteração da homeostase

- Patologia do crânio, pescoço, olhos, nariz, ouvidos, dentes, seios perinasais,...

- Doença psiquiátrica

Quadro 3. Classificação das cefaleias - International Classification Headache Disorder (ICHD)

antecedentes familiares desta patologia, sobretudo do lado materno, em mais de $80 \%$ dos casos. Pode ter um grande impacto na qualidade de vida das crianças e das suas famílias, levando a uma diminuição do envolvimento nas atividades da escola, em casa e nas atividades sociais.

A enxaqueca sem aura é a forma mais frequente em pediatria (60 a $85 \%$ dos casos). Geralmente apresenta-se como uma cefaleia de curta duração (dura mais de uma hora, geralmente não mais de 24 horas), pulsátil, localizada à região frontal ou temporal. A natureza hemicraniana da enxaqueca é rara na criança pequena e vai aumentando de frequência com a idade. Uma característica importante são as náuseas e os vómitos que por vezes são mais incomodativos que as cefaleias e que também podem ser acompanhados por dores abdominais. A foto e a fonofobia associadas podem-se inferir pelo comportamento da criança, que geralmente interrompe a atividade em curso e que melhora com o repouso e o sono. Os pais frequentemente referem que o filho fica pálido, com olheiras, irritável e menos ativo, procurando espontaneamente a calma, o escuro e o silêncio. $\mathrm{Na}$ escola, deita a cabeça nos braços sobre a mesa.

$\mathrm{Na}$ enxaqueca com aura, esta precede o início da cefaleia. Caracteriza-se por episódios recorrentes de sintomas neurológicos reversíveis (visuais, sensoriais ou outros) que surgem gradualmente e que duram minutos, seguido de cefaleias com características de enxaqueca. As manifestações mais frequentes são as visuais com queixas de escotoma (diminuição da área de visão dentro do campo visual), hemianópsia, fosfenos (estrelinhas), fotopsia (lampejos de luz), teicopsia (linhas brancas em ziguezague), amaurose transitória, micro ou macropsia.

Para o diagnóstico de enxaqueca de acordo com os critérios da ICHD-3, são necessários pelo menos cinco episódios com as seguintes características: cefaleia com duração de duas a 72 horas; cefaleia com pelo menos dois dos seguintes sinais: localização uni ou bilateral, pulsátil, intensidade moderada a grave, agrava com a atividade física de rotina (ou causa a sua evicção); durante a cefaleia pelo menos um dos seguintes sinais: náusea e/ou vómito, fotofobia e fonofobia (comportamento...).

Podemos dizer que estamos perante um estado de mal migranoso quando temos uma 
cefaleia tipo enxaqueca de grande intensidade e duração superior a 72 horas.

Equivalentes de enxaqueca.

Nas crianças existem síndromes diferentes que podem ser considerados como variantes da enxaqueca, sendo o seu diagnóstico difícil porque a sintomatologia frequentemente não inclui cefaleias. Os síndromes episódicos que podem ser associados a enxaqueca ou síndromes periódicos da criança incluem a perturbação gastro-intestinal recorrente (vómitos cíclicos, enxaqueca abdominal), a vertigem paroxística benigna da criança e o torcicolo paroxístico benigno.

O síndrome de vómitos cíclicos é caracterizado por episódios recorrentes de vómitos e náuseas intensas que ocorrem de uma forma estereotipada, duram geralmente um a dois dias, sendo muito caraterística a natureza ciclíca com que surgem. São tipicamente auto-limitados, com períodos de completa normalidade entre estes episódios. A idade de início é aproximadamente de cinco anos e geralmente desaparecem por volta dos dez anos. A história e o exame físico não revelam sinais de doença gastro-intestinal.

A enxaqueca abdominal é uma situação recorrente, idiopática, caraterizada por dor abdominal episódica da linha média, que se manifesta em episódios que duram entre duas a 72 horas, com normalização entre estes. A dor é moderada a intensa, interferindo nas atividades da vida diária e associada a sintomas vasomotores, náuseas e vómitos.

A vertigem paroxística benigna é uma perturbação da infância e da idade escolar (embora possa ocorrer em crianças mais velhas) em que surgem episódios breves e recorrentes de desequilíbrio, de início súbito, em que a criança parece ficar assustada e com medo, chegando por vezes a vomitar. Têm intensidade máxima no seu início, a criança pode ser incapaz de se manter em pé, fica pálida, deitando-se no chão ou agarrando-se a alguém; mantém-se sempre consciente. Os episódios geralmente são raros, duram minutos e podem recorrer a intervalos irregulares.

O torcicolo paroxístico benigno carateriza-se por episódios recorrentes de inclinação lateral da cabeça, por vezes com ligeira rotação, que resolvem espontaneamente em minutos ou dias. Ocorrem em lactentes e crianças pequenas, com um pico de incidência entre os dois e os oito meses. A cabeça da criança pode ser colocada em posição neutra durante os ataques, apesar de alguma resistência poder ser encontrada. Por vezes está associado a palidez, irritabilidade, mal-estar, vómitos e ataxia.

\subsubsection{Cefaleias de tensão}

São uma causa comum de cefaleias na criança e no adolescente, sendo a idade média de início aos sete anos, tendo mais de metade destes doentes também enxaqueca. A dor é tipicamente bilateral, tipo pressão ou aperto, predomínio vespertino, de intensidade ligeira a moderada e que não agrava com a atividade física de rotina. Não está associada a náuseas ou vómitos, mas fono ou fotofobia podem estar presentes.

Para o diagnóstico de cefaleias de tensão de acordo com os critérios da ICHD-3, são necessários pelo menos dez episódios com as seguintes características: cefaleia com duração de 30 minutos a sete dias; cefaleia com pelo menos dois 
dos seguintes sinais: localização bilateral, tipo pressão / aperto (não pulsátil), intensidade ligeira a moderada, não agravada com a atividade rotineira; ambos: ausência de náuseas e/ou vómitos, fotofobia ou fonofobia.

\subsubsection{Cefaleia por sinusite}

É uma causa rara de cefaleia na criança. Quando a sinusite está presente a criança tem um ar doente, muitas vezes febril, com congestão ou corrimento nasal e dificuldade em manter a via aérea limpa. A dor é localizada à percussão dos seios maxilares e ou frontais, enquanto que a inflamação dos seios etmoidais e esfenoidais causa dor a nível da linha média por trás do nariz.

Não esquecer que os seios maxilares e etmoidais estão presentes desde o nascimento e são os mais frequentemente envolvidos nas crianças. O seio frontal desenvolve-se entre os seis e os oito anos e o seio esfenoidal durante a puberdade.

Para atribuir a cefaleia a uma sinusite tem que haver evidência imagiológica ou clínica de uma sinusite aguda ou agudização de uma sinusite crónica.

A cefaleia é tipo pressão, geralmente bilateral, pior durante a manhã (congestão dos seios perinasais na posição supina durante a noite) e dura vários dias. As dores relacionadas com as sinusites maxilar ou frontal são referidas à região inter, supra ou retro-orbitária. A dor da sinusite etmoidal localiza-se na linha média, entre os olhos, perto da hipófise e dos seios cavernosos e necessita de uma terapêutica mais agressiva.

A tomografia axial computorizada crânio-encefálica (TAC-CE) é muito sensível na identificação da sinusite, mas geralmente não é necessária. É frequente, quando solicitada por outros motivos, mostrar evidência de sinusite assintomática.

\subsubsection{História clínica}

\subsubsection{Anamnese}

A história clínica minuciosa é fundamental na avaliação destes doentes. A anamnese cuidadosa, incluindo a história familiar (nomeadamente na enxaqueca) e um exame físico detalhado são os fatores mais importantes para chegar a um diagnóstico clínico correto. A abordagem inicial implica saber se estamos perante uma cefaleia primária ou secundária e dentro destas qual é o diagnóstico mais provável, para depois podermos identificar quais as crianças que necessitam de investigação complementar e quais as que necessitam de algum tipo de terapêutica.

$\mathrm{Na}$ anamnese de uma criança com cefaleias, a sua classificação e o diagnóstico correto irão depender das informações recebidas sobre a sua dor. Claro que quanto mais nova for a criança e menor for o tempo de evolução das suas queixas, maior será a dificuldade em obter estes dados e por isso temos muitas vezes que procurar informações indiretas que nos permitam caracterizar os sintomas.

Na caraterização da cefaleia é importante questionar sobre a idade / data de início das queixas, o seu padrão evolutivo (aguda, recorrente, crónica progressiva ou não progressiva), tipo de dor (pulsátil, aperto,...), localização (generalizada, hemicrânia,...), intensidade (pode ser inferida pelo comportamento da criança: se continua a brincar ou se pára e tem que se deitar), duração e frequência dos episódios, horário (matinal, 
vespertino, noturno; dias da semana). É importante pesquisar a presença de pródromos (sintomas que precedem ou anunciam a crise), de sintomas associados (náuseas, vómitos, fotofobia, fonofobia,...), factores de alívio ou agravamento (ingestão de determinados alimentos, jejum prolongado, sono excessivo, sono não reparador, stresse, ciclo menstrual, esforço físico), alterações de comportamento e qual a resposta aos analgésicos. A mudança de posição da cabeça e as manobras de Valsalva que agravam de modo claro a cefaleia, devem levar à suspeição de uma patologia que curse com hipertensão intracraniana. 0 sucesso escolar, as dificuldades de aprendizagem, a exigência posta nos resultados escolares pelo próprio ou pela família, a sobrecarga de horários e atividades extra-curriculares, a prática desportiva, as relações com os pares, a personalidade da criança e outros fatores psico-sociais também podem ser relevantes para o diagnóstico.

Não nos devemos esquecer de inquirir sobre a qualidade do sono. Nos últimos anos tem-se dado grande importância à relação estreita que existe entre o sono e cefaleias. Sabemos que as perturbações do sono estão associadas a cefaleias e que episódios de cefaleia podem ocorrer durante e após o sono e em relação com vários ciclos de sono. Por outro lado, as próprias cefaleias podem interferir no sono e estar associadas a vários tipos de problemas, que incluem um sono insuficiente, dificuldades em adormecer, ansiedade relacionada com o sono, sono agitado, despertares noturnos, pesadelos e fadiga durante o dia. Sabemos que um excesso de sono, a sua privação, um sono de má qualidade ou de duração inadequada são fatores desencadeantes de cefaleias. Nas crianças, a perceção de um problema de sono por vezes é difícil e é subestimado. Além disso, é mais fácil para uma criança queixar-se de dores de cabeça do que referir que tem um sono de má qualidade. Assim, o sintoma "cefaleia" deve ser avaliado de diferentes pontos de vista, incluindo uma avaliação cuidadosa da higiene do sono e dos seus problemas (a cefaleia matinal pode ser um sinal de apneia obstrutiva do sono nas crianças!).

\subsubsection{Exame físico}

É importante a realização de um exame objetivo completo com observação cutânea (i.e. manchas café-com-leite, entre outras), percussão dos seios faciais, avaliação da tensão arterial e um exame neurológico cuidadoso que inclua estado mental, nervos cranianos, reflexos e provas de coordenação. A fundoscopia é fundamental para excluir a presença de papiledema, atrofia ótica ou hemorragias retinianas; a ausência de edema papilar não exclui completamente a possibilidade de hipertensão intra-craniana.

\subsubsection{Exames complementares de}

\section{diagnóstico}

Uma história clínica cuidadosa e reavaliações regulares são os principais fatores e os que apresentam melhor custo-eficácia, mesmo em crianças em idade pré-escolar. Um exame normal apresenta uma relação fortemente positiva com a ausência de um processo intracraniano grave em doentes pediátricos e adultos e permite excluir na grande maioria dos casos a necessidade de investigação adicional.

O electroencefalograma (EEG) raramente é informativo nos casos de cefaleias e a presença de alterações inespecíficas pode confundir o normal processo diagnóstico. 
A Punção Lombar (PL) deve ser realizada nos casos de suspeita de infeção/inflamação do sistema nervoso central, alterações na pressão do líquido cefalorraquídeo e nos doentes imunocomprometidos. Na suspeita de uma lesão estrutural focal com efeito de massa, em que o risco de herniação é elevado, a PL pode estar contra-indicada e deve ser precedida de um exame de neuroimagem.

$O$ exame de neuroimagem deve ser feito apenas em casos selecionados e sempre em função da história clínica, nomeadamente nos casos de cefaleia de grande intensidade de início recente, alteração do padrão de cefaleia, cefaleia crónica progressiva e qualquer alteração no exame neurológico. A ressonância magnética crânio-encefálica é o método imagiológico de escolha, enquanto que a TAC-CE é uma mais valia em situações de emergência ou quando a ressonância não está disponível ou está contra-indicada (i.e. uso de pacemaker).

As guidelines da American Academy of Neurology e "Practice Committee of the Child Neurology Society" recomendam a realização de exame de neuroimagem nos seguintes casos: alterações no exame neurológico, apresentação atípica (vertigem, vómitos incoercíveis ou despertares noturnos por dor), evolução recente (menos de seis meses), alteração recente do tipo de cefaleia, agravamento progressivo da dor, idade inferior a seis anos, ausência de história familiar de cefaleia primária, cefaleia occipital, cefaleia de novo numa criança imunocomprometida; primeira ou pior cefaleia sentida pela criança, sinais e/ou sintomas sistémicos, cefaleias associadas a confusão, alteração do estado de consciência ou sinais neurológicos focais.
Têm indicação para exame de neuroimagem as cefaleias com as seguintes características:

patologia antecedente (tumor operado, derivação ventrículo-peritoneal); idade inferior a três anos; padrão progressivo ou alteração recente das características da cefaleia; presença de cefaleias e vómitos matinais; agravamento por manobras de Valsalva, tosse ou mudanças bruscas de posição; instalação aguda de cefaleia lancinante; lateralização fixa ou localização occipital persistente; alterações no exame neurológico.

\subsubsection{Tratamento}

A terapêutica da cefaleia deve ser individualizada, tendo em consideração o grau de interferência na vida diária da criança. Deve incluir a evicção de fatores desencadeantes, o tratamento das crises e, se necessário, tratamento profilático.

O plano de tratamento deve ter em consideração estratégias de natureza farmacológica e não farmacológica de acordo com o comprometimento funcional da cefaleia e sintomas associados. Nem todas as crianças necessitam de terapêutica farmacológica.

O tratamento não farmacológico implica medidas de higiene do sono e hábitos de vida saudáveis (alimentação adequada, prática de exercício físico); evitar fatores desencadeantes conhecidos (jejum prolongado, stresse, certos alimentos,...); permitir que a criança fique num quarto escuro, sem ruídos, e, eventualmente, recorrer a técnicas de relaxamento e biofeedback. O repouso em ambiente adequado (com pouca luminosidade e silencioso) e um breve período de sono são muitas vezes eficazes para abortar uma crise de enxaqueca. Na infância esta medida é mais fácil de 
adotar do que na idade adulta, pelo que deve ser encorajada, evitando assim a utilização excessiva de analgésicos.

O tratamento sintomático da dor deve ser administrado precocemente após o início das queixas, sendo o fármaco de primeira linha o ibuprofeno numa dose de 7,5 a $10 \mathrm{mg} / \mathrm{kg}$. A sua eficácia é superior à do paracetamol e de mais rápida ação. Não deve ser usado mais de duas a três vezes por semana pelo risco de cefaleia por abuso medicamentoso - atenção à cefaleia rebound por analgésicos!

Se a criança tiver náuseas e vómitos podemos recorrer à terapêutica retal com analgésicos ou, eventualmente, a anti-eméticos (metoclopramida, ondansetron).

Os triptanos (agonistas dos receptores 5-HT da serotonina) podem ser usados em casos selecionados em adolescentes com enxaqueca, nomeadamente o almotriptano, o sumatriptano e o zolmitriptano nasal ou oral.

O tratamento profilático da enxaqueca está reservado para os casos em que as crises são frequentes (superior a uma a duas por semana ou a três a quatro vezes por mês), com implicações nas atividades da vida diária (faltas à escola) ou quando existem crises de grande intensidade ou complicadas (i.e. enxaqueca hemiplégica). É importante pedir à criança para fazer um registo "diário" das cefaleias, para ter um conhecimento correto da sua frequência e para depois avaliar a resposta ao tratamento. Os medicamentos mais habitualmente utilizados são o propranolol, a flunarizina e, nos adolescentes, a amitriptilina, o topiramato e o valproato de sódio. O tratamento deve ser feito durante um período de quatro a seis meses, com introdução e suspensão graduais.
Não esquecer de garantir que a criança não apresenta nenhuma contra-indicação para o uso do propranolol (asma, diabetes, patologia cardíaca).

O tratamento do estado de mal migranoso implica o repouso em quarto escuro e silencioso, hidratação endovenosa, antieméticos/procinéticos (metoclopramida, clorpromazina), corticoterapia e valproato de sódio endovenoso.

\section{Leitura complementar}

Cefaleia no Serviço de Urgência - protocolo do Hospital Pediátrico 